\title{
Sense and the Identity Conception of Truth
}

\author{
S. J. Methven
}

\begin{abstract}
The identity conception of truth holds that a thinkable is true just in case it is a fact. As such, it sets itself against correspondence theories of truth, while respecting the substantive role played by truth in respect of enquiry. In this article, I motivate and develop that view, and, in so doing, promote a particular conception of sense. This allows me to defend the view from two substantial criticisms. First, that the identity conception of truth is incoherent in respect of its treatment of objects in the realm of reference, and, second, that it is committed to a view of the world in which ordinary objects have no place.
\end{abstract}

\section{INTRODUCTION}

I wish to defend a conception of truth, which takes as a natural, though perhaps not necessary, starting point a truistic statement reflective of perfectly ordinary ways in which we speak: All and only truths are facts. ${ }^{1}$ This statement requires some development in order to be expressive of the view that I want to defend; in particular, it must be made clear that it is a statement which identifies truths with facts. That development will come shortly, and it will require an account of what kinds of things truths are. But since this statement identifies truths with facts, that will also be an account of what kinds of things facts are.

I say that this statement is truistic because, leaving aside for the moment distinctively philosophical concerns about the natures of truths and facts, its negation is not something that anybody who understands how to use the words "truth" and "fact" could ever be in a position to affirm: There are some truths which are not facts, or there are

\footnotetext{
1 This is not a necessary starting point because one might be, as Austin was, resistant on etymological grounds to associating truths too closely with facts. Austin argues, against Strawson ("Fact', like 'true', 'states', and 'statement', is wedded to 'that'-clauses; and there is nothing unholy about this union." Strawson, 1950, p. 136), that the use of "fact" in that-clauses is a relatively recent linguistic innovation, dating only to the 18th century (Austin, 1979, p. 163). But his research is out of date. In its earlier recorded uses (1487), a fact was a completed deed or action. The Oxford English Dictionary now shows that uses of "fact," which connoted truth as opposed to action, are recorded as early as 1531. Further, it lists an instance of its use in that-clauses in, at least, 1617, and the related phrase, generally associated with a gerund, "fact of" is recorded in 1578 (fact, n., int., and adv., June 2017: OED Online). At any rate, it is not clear to me what weight such evidence ought to be assigned: It was only in the 16th century that the verb "to fault" took its current transitive form according to which to fault someone is to blame them, having in previous centuries had only an intransitive use to express a lack in something or someone (fault, v., June 2017: OED Online). But it would be bizarre to argue, on those grounds, that "to fault" is not wedded to a grammatical object, as though a person could not now be wedded to her partner because she was previously wedded to no-one or, perhaps more fairly to Austin's example, that she could not be wedded to her because she at times consorts with others. (I thank Peter Sullivan for drawing Austin's discussion to my attention).
} 
some facts which are not truths. Nobody is, as it were, allowed in everyday speech to say either "That is a truth but it is not a fact" or "That is a fact but it is not a truth."

Everyday speech aside, some philosophers have found themselves able to say each of these things, or variants of each of these things. In particular, correspondence theorists must, if speaking plainly, say as much of every truth (as it were, pointing to the heavens) and every fact (as it were, pointing to the earth). Being able to do so must then rest upon philosophical conceptions of facts and truths which, according to the identity theorist, effect a double vision so that there appear two things where really there is only one. An identity conception of truth must then supply a picture of facts and of truths which clears our vision, thereby allowing us to accept the truistic statement with which I began not only as a record of our everyday sayings but as a substantive and correct philosophical thesis. I think that Jennifer Hornsby has provided such a picture, and it is her view, or at least her view as I have found it, that I shall try to defend and develop here. ${ }^{2}$

I begin, in Section 2, by characterising the view, before motivating it further in section 3. In Sections 4 and 5, I deal with objections that have been made against the identity conception of truth on the grounds that the view is (a) incoherent in respect of its treatment of objects in the realm of reference and (b) such as to commit the identity theorist to a view of the world in which ordinary objects have no place. Answering those objections will allow me to develop an account of how the identity theorist ought to conceive of the relation between (ordinary) objects of reference and what is thinkable. It will depend upon showing (a) how a correct understanding of sense may be seen to allow ordinary objects to feature in the kinds of things that truths are and (b) how the identity theorist, while taking no stand on what objects there are, should not be saddled with a characterisation of the world from which ordinary objects are absent.

\section{THE IDENTITY CONCEPTION}

Here is the Identity conception's central thesis:

1. A thinkable is true if and only if it is a fact. ${ }^{3}$

The reference of "it" in (I) is to the thinkable in question so that it follows that all and only true thinkables are facts. There are thus two claims that must be addressed: First, that thinkables are the kinds of things which are true or false, and, second, that thinkables, when true, are facts. ${ }^{4}$

\footnotetext{
${ }^{2}$ Hornsby, 1997, 1999. Versions of the identity conception of truth were, at one time or another, endorsed by Moore and Russell; a rather different view was pressed by Bradley. See Cartwright, 1987, Candlish, 1989, Baldwin, 1991, and Candlish, 1999b for discussion of these views and their interconnections.

${ }^{3}$ In her 1997 publication, Hornsby prefers the formulation: True thinkables are the same as facts (Hornsby, 1997, p. 2). The formulation that I prefer is a version of one that Hornsby has asserted on a different occasion: A thinkable is false if and only if it is not a fact (Hornsby, 1999, p. 243). As Hornsby provides a prescription for amending this formulation, if one doubts bivalence (delete "if and" from "if and only if"), I take it that her own commitments would ensure that no objection can arise to my reformulation.
}

${ }^{4}$ As my starting point was the workaday claim that all and only truths are facts, it may be objected that there is, in the move from that claim to the claim that all and only true thinkables are facts, an as yet 
The substantive commitment of the identity conception enters when the identity theorist says something about what kinds of things are the primary bearers of truth: a thinkable is true if and only if it is a fact. The notion of a thinkable is McDowell's (1994): A thinkable is something that can be thought, where a distinction is drawn between an act of thinking and the content of that act. ${ }^{5}$ Let us say, simply and in accord with the beliefs of many philosophers, that a thinkable is what is thought or asserted or believed or known when something is thought or asserted or believed or known. The modal component of the notion of a thinkable must surely make it clear that a thinkable need neither ever have been nor ever be thought or asserted or believed or known in order to be the kind of thing that can be thought or asserted or believed or known. ${ }^{6}$ The thinkable that the Cambridge soil is rich in lime was never thought by Plato, was just thought, and, indeed, asserted, by me, and, though it is unlikely, may never be thought again. The thinkable that the Cambridge soil is rich in lime is furthermore true. ${ }^{7}$ Of course, that the Cambridge soil is rich in lime is a thinkable that Plato could not, contingently, think, lacking as he did a number of concepts requisite to its apprehension. Likewise, there are even now, it seems certain, thinkables that we cannot, contingently, think for lack of conceptual maturity, which may nonetheless be true. And there is no reason to suppose that there might not be thinkables which no thinker can ever think, which may nonetheless be true. ${ }^{8}$

unjustified premise to the effect that all and only truths are true thinkables. Let us assume that the objector accepts (a) that all and only truths are facts and (b) that, given the argument following this note in the text, thinkables are the primary bearers of truth; then an objection to this premise would be one which asserted that the primary bearers of truth, when true, were not truths. "When we speak of truths," she might say, "we are speaking of facts, but when we speak of the kinds of things that are true, we are speaking of thinkables. For just as a fact cannot be true, nor can a truth be true, while a true thinkable not only can be true, it is true. A truth and a thinkable cannot be the same thing if something can be correctly predicated of one but not of the other." The way in which it is incorrect to say of a truth that it is true, however, is that to do so is to say something redundant; it is not, therefore, false or nonsensical to say of $p$, if it is a truth, that it $-p$-is true, just as it is not false or nonsensical, though certainly redundant, to say of $a$, if it is an existent, that it-a-exists. One consequence of this is that, since the identity theorist takes all and only facts to be true thinkables, she must diagnose the infelicity of saying of a fact that it is true, that it likewise involves redundancy. I merely note that while the sentence "that fact is true" may make the ear squirm, it is nothing as to the mind's revolt upon receipt of the sentence "that fact is not true." See Künne (2003, p. 10) and Johnston (2013, n.5) for versions of this objection.

${ }^{5}$ Without proper regard for this distinction, one is liable to conflate a thinkable with the mental activity that constitutes a subject's thinking a thought. That psychologistic conflation is then liable to lead to the objection that the identity conception entails idealism, for how else could thoughts, in that sense, be facts? That such an objector has taken a wrong turn can be seen by reflection on that fact that Frege, no idealist, took true Thoughts to be facts; for Fregean Thoughts, whatever else they may be, stand as obvious candidates for thinkables (Frege, 1956, p. 307).

${ }^{6}$ We might, in so agreeing, then find ourselves saying that a thinkable is a proposition, correctly construed, or a propositional reference, correctly construed, or a propositional content, correctly construed. The distinction to which I am drawing attention here is well-worn, but what I wish to avoid is a discussion of the correct construal of these entities, if there are any, and am content to rest with the pre-philosophical conception according to which there is something that you and I believe, assert, or know in common when we believe, assert, or know the same thing. I thus follow Hornsby and McDowell (though I do not say their reasons are the same) in avoiding the philosophically contentious but more familiar term "proposition" with which the distinction is usually associated.

7 That it is thinkables, rather than sentences, that are true cannot be made clearer but by observation of the fact that while Plato never asserted the thinkable that I have just thought, had he done so, and were I to speak his language, I would have recognised that what we took to be true was just the very same thing, namely, that the Cambridge soil is rich in lime.

8 There is here an issue concerning the modality of that "can" that I cannot skirt, for it might be asked: What could an essentially unthinkable thinkable be? This point was most usefully pressed by Stephen Williams, who raised the following example. Let $c$ be a real number the canonical specification of which is 
What of the claim that true thinkables are facts? ${ }^{9}$ Hornsby draws her identity theory of truth from McDowell's (1994, p. 27) view of the relationship between a thinkable and the world:

There is no ontological gap between the sort of thing one can mean, or generally the sort of thing one can think, and the sort of thing that can be the case. When one thinks truly, what one thinks is what is the case.

A defence of this will begin in the next section and continue into Sections 4 and 5. For now, I simply press the naturalness of such a way of speaking. When someone believes that the sun is setting then, if the sun is setting, what they believe is just what is the case. That is, what they believe is a fact. No gap between what they believe and what obtains can feature in an account of this state of affairs-their believing something true and the content of their belief being a fact.

The introduction of thinkables allows us to say that (a) any act of thinking truly has as the content of that act a true thinkable. Since when one thinks truly, what one thinks is what is the case, (b) true thinkables are what are the case. If, like Wittgenstein (1922, pp. 1-1.1), one holds further (c) that the world is all that is the case and (d) that the world is the totality of facts so that (e) all that is the case is the totality of facts, the identity conception of truth follows from (b) and (e): A thinkable is true if and only if it is a fact. There is also here a conception of the world-the world is the totality of true thinkables.

Someone still in the grip of a certain picture will be likely to object that this gets something wrong about facts and their constituents. Before discussing variations of this objection in Sections 4 and 5, however, I wish first to advertise the virtues that the identity conception might be thought to possess over competitor conceptions of truth.

\footnotetext{
not recursively specifiable. Since the concept "is identical to $c$ " is not graspable by a finite mind, any thinkable which concerns that concept is unthinkable. Let one such thinkable be that $c$ is identical to Julius Caesar. Such a thinkable would be unthinkable, but is nonetheless plainly false. Leaving aside infinite minds as providing an unsatisfactory solution to this puzzle, rendering as it does the ungraspability of the concept "is identical to $c$ " a merely medical matter, in Russell's phrase, what should one say here? Well, I think that one should say that it really is an open question in the philosophy of mathematics as to whether there could be mathematical truths of the form " $c$ is not identical to Julius Caesar." Indeed, it was Russell's failure to see the puzzle suggested in Ambrose's account of finitism that caused him to take the short way with her that he did (Ambrose, 1935a, 1935b; Russell, 1936). Such a reply as mine is, however, not yet post hoc, for it may be that it is precisely an attachment to a correspondence conception of truth which underwrites the traditional account of the operation of the universal quantifiers over infinite domains. If that is so, then the objection begs the question, but I cannot pursue this issue here.

${ }^{9}$ It is a mistake to take the kind of identification involved in (I), as Künne (2003, p. 6) does, as being of the form: for all $x, x$ is a true proposition iff there is some $y$ such that $y$ is a fact and $x=y$. If I tell you that all messy dogs are mutts, I am not thereby inviting you to suppose that there is, for each messy dog, some mutt with which it is identical. I am not, in particular, thereby inviting the question, asked of some messy dog: to which mutt is it identical? For the kind of objection that can arise from this misreading, see Candlish (1999b) and Beall (2000) for a response.
} 


\section{CORRESPONDENCE AND DEFLATION}

(I) A thinkable is true if and only if it is a fact.

The conception of truth elucidated by this statement is compelling for two reasons:

1. It makes no attempt, contra correspondence views, to explain, reduce, or analyse truth, while, contra deflationism, retaining a substantive role for that concept in respect of the use to which it is put in enquiry.

2. In setting aside entrenched philosophical characterisations of factscharacterisations that, it is sometimes forgotten, one is under no compulsion to entertain-it quells two related temptations: the temptation to think in correspondence terms and the temptation to avoid the consequences of those terms by adopting a deflationary approach and displacing truth from its proper place in our thought.

I have been careful to avoid the term "identity theory of truth," 10 for the simple reason that a theory of $X$ might at least be expected to tell us what $X$ is. The identity conception makes no such attempt-indeed, were it to do so, the central platitude from which it takes off would be uninformative in the absence of an account of facts, and straightforwardly circular were such an account to make recourse to notions such as what is the case or what obtains, or, of course, truth. Part of the point of the identity conception is to rescue the term "fact" from philosophical kidnap, by aligning it with a different notion, that of a true thinkable, and so to set itself against correspondence conceptions. Another part of the point of the identity conception is to embrace both truth's unanalysability and its substantiality.

One kind of correspondence theorist does offer a theory of truth and so denies its unanalysability, holding instead that we can give a reductive account of the concept in terms of a relation holding between a truth-bearer and a "worldly" entity other than the objects and properties of ordinary reference. Frege provides a general argument against truth's analysability in terms of any more primitive notion to the extent that any such putative analysis must collapse into incoherence. It has often been thought that the argument seeks to generate a regress and does not succeed insofar as it conflates the conditions of something's being true with what an enquirer must discover in order to determine whether it is true. ${ }^{11}$ Frege $(1956$, p. 291), however, speaks not of regress but of circularity:

[Any] attempt to define truth also breaks down. For in a definition certain characteristics would have to be specified. And in application to any particular case the question would always arise whether it were true that the characteristics were present. So we should be going round in a circle. So it seems likely that the content of the word 'true' is sui generis and indefinable.

\footnotetext{
${ }^{10}$ I am not so careful to avoid the term "identity theorist," but only because "conceive," unlike "theorise," takes an agentive suffix only most unhappily.
}

11 See, for instance, Dummett (1981); Künne (2003). 
It may be more fruitful to see Frege's argument as aimed at the attitude that one must take towards the sentence of the truth theory itself: when he writes "any particular case," he intends "any particular proposed definition of truth." To put forward an analysis of truth is to put forward a substantial and non-trivial claim about the nature of truth, and in putting it forward, the theorist is, of course, putting it forward as true. That is, the theorist asserts of the definition itself that "the characteristics" captured by the definiens of that very definition are present. ${ }^{12}$ One might now ask, as Frege does, what would be required of an enquirer seeking to determine whether the proposed analysis is true. ${ }^{13}$ Thinking this question through raises a dilemma. For one means by which we test an analysis is to search for counterexamples. In so doing, we consider cases in which the "characteristics" of the analysandum are present and establish necessity by noting that those of the analysans are present also; sufficiency is established by considering the reverse, checking that cases in which the "characteristics" of the analysans are present are also cases in which those of the analysandum are present. What enables us to do so is that, if the analysis is substantive, the analysans and analysandum differ conceptually, and their differing conceptually entails their invoking different criteria of application to cases. If the analysis is to be substantive then, while it may never, if it is correct, be possible to find a case in which the characteristics of one side of the analysis are present and the characteristics of the other absent, it should be possible to identify a case in which the characteristics of one half are present without requiring knowledge of the characteristics of the other half in order to identify it. That is, one ought to be able to determine of a case whether it satisfies one of the sides of the analysis independently of invoking the conceptual resources involved in determining whether it satisfies the other.

Consider a proposed analysis of truth: It is true that $P$ iff $P \varphi s$, for some predicate or predicates $\varphi$ and claim $P$. The question, which it is now incumbent upon the theorist to answer, is this: What resources does the enquirer have available for determining, of some case, whether $P \varphi s$ ? Or, put another way, what are the characteristics of $P$ s $\varphi$-ing which are not the characteristics of its being true that $P$ ? For an answer to begin to approach adequacy, it must furnish the enquirer with a means of determining whether or not $P \varphi s$ which does not invoke the means by which she might determine whether it is true that $P$. For, if in determining whether $P \varphi s$ one is merely determining whether it is true that $P$, then one has done nothing to substantiate an analysis which purported to be substantive. Instead, one has substantiated an analysis which is merely verbal insofar as, whatever the phrasing of $\varphi$, in enquiring whether or not $P \varphi \mathrm{s}$, one has invoked the very concept-truth - that one sought to analyse. To do so is, then, simply to stutter-to move in the very smallest of circles.

Frege's criticism, however, is not conclusive; it seems to him only "likely" that it is impossible to identify the characteristics of the property invoked in the analysans

\footnotetext{
12 Someone might suggest that it need not follow that, if it is asserted that $P$, it is thereby asserted that it is true that $P$. But such a suggestion amounts to the abandonment of the Equivalence Principle, namely, it is true that $P$ iff $P$. As Dummett (1981, p. 444) points out, so doing would be to sever the link between a number of cognitive attitudes and truth, insofar as it would allow that someone might be in the position of believing, knowing, or asserting that it is true that $P$ without being in the position of believing, asserting, or knowing that $P$.
}

${ }^{13}$ I shall, throughout, refer to the following argument as "Frege's argument," without thereby wishing to attribute the argument to Frege as a matter of historical fact. 
without bringing to bear the conceptual resources associated with truth. But there are reasons to suppose it is in fact impossible. For let us suppose that $\varphi$ denotes a property or properties, recognition of the characteristics of which is possible independently of recognition of the characteristics of truth and that an enquirer might therefore be in a position to determine whether $P \varphi$ s without having first to determine whether it is true that $P$. The demands that this proposal makes on a candidate $\varphi$, seem, however, impossible to meet. For consider that there is no single means by which one recognises the presence of truth: the means by which it is determined whether claims of mathematics, geography, personal psychology, and theoretical physics are true differ radically. What is required of $\varphi$ is that the means by which it is determined that it obtains of each of these claims be other than the means by which it is determined whether they are true, for otherwise the first horn of our dilemma reasserts itself. But what means do we have available, other than those that we use to enquire into the truth of these diverse claims, to substantiate that $\varphi$ obtains of them and obtains of them just in case they are true? In order to establish the truth of Fermat's last theorem, I must furnish a proof. But what must I do to establish that Fermat's last theorem $\varphi s$ ? A proof will clearly not suffice, for if it did, that would be to establish that Fermat's last theorem $\varphi s$ only via the means by which it is determined that it is true. That would be to encounter the first horn of the dilemma. But what means, other than proof, could there possibly be of establishing that Fermat's last theorem $\varphi s$, such that its $\varphi$-ing entails its truth?

The lesson of Frege's argument is startling: Any reductive theory of truth must either collapse into vacuous circularity or else must furnish the enquirer with an independent means of determining that a claim possesses the relevant reduction property, which is both not a means of establishing its truth and yet at the same time necessary and sufficient for its truth. That would be, essentially, to provide a means, if the analysis were true, of establishing the truth of a range of claims which was independent of the means by which we establish their truth. And that is a nonsense. We thus see that no reductive theory of truth can avoid circularity: There is no gap between truth and the activities of truth-seeking into which the crowbar of analysis may be introduced. What that reveals is that the truth of a claim such as "It is true that $P$ iff $P$ corresponds to reality" can only be, if it is true, platitudinous, and therefore empty of the kind of insight that the correspondence theorist purports to find. That is, of course, also the status of the identity theorist's claim: A true thinkable is a fact. But it was never a part of the identity theorist's aims to recover an insight into the nature of truth from that statement.

The above argument takes aim at what I called "one kind of correspondence theorist," and while it may yet be that there is only one kind of correspondence theorist, Crispin Wright takes himself to have discovered another. For Wright, the most fruitful way in which to regard the defender of the correspondence conception is not as a philosopher in search of a reductive analysis of the concept of truth but rather as a philosopher who has in hand already an account of the nature and structure of the property of truth. His correspondence theorist is characterised as holding that truth is "a relational characteristic whose terms are respectively propositions - to pick one among the possibilities - and non-propositional items - facts or states of affairs" (Wright, 1998, p. 35), and this conception of correspondence, we are told, "shorn of any further analytical or explanatory obligations, comes across as highly common-sensical" (Wright, 1998, p. 37). But it cannot be an article of common sense unless we are told what a fact or a state of affairs is intended to be, and in the hands of the correspondence theorist, these entities stand in no relation to the kinds of everyday sayings-sure witnesses to 
common sense-with which I began this essay. What certainly is an article of common sense is the claim that the truth or otherwise of a sentence, belief, thought, and so forth is dependent on two things: what the content of those objects says and whether the world is as it says it is. Undoubtedly, that claim embodies a relational commitment, but we need not recover from it any correspondence holding between one kind of object-a true proposition - and another - a fact or state of affairs-which is not captured by the central claim of the identity conception.

Indeed, that Wright does not have a clear conception of the relationship he attributes to his correspondence theorist is evinced by his criticism of intrinsicism, the view that truth is a non-relational property, intrinsic to the proposition in question. This view is, he thinks, obviously false, since "the truth-value of any contingent proposition must covary with hypothetical changes in the characteristics of things it concerns - so that a hypothetical change, for instance, in the location of my coffee cup may entail an alteration in the truth-value of the proposition that there is no coffee cup on my desk, even though that proposition and the particular coffee cup in question are quite distinct existences" (Wright, 1998, p. 37). The identity theorist can only agree with his assessment-whether a thinkable is true, that is, whether it is or is not a fact will depend on how the world is. If the cup is not on the table, then quite obviously it will not be a fact that it is.

The difficulty here is that Wright is engaging simultaneously with a notion of correspondence which arises from two distinct, as it were, programmatic aims. The latter, weaker notion with which the Identity theorist has no quarrel is that one which arises in response to the threat of idealism inherent in the coherentist programme; it seeks to vouchsafe the normative pull of truth in respect of our practices of enquiry, to justify or explain our having that property as our aim. ${ }^{14}$ The former, stronger notion arises from a different aim, namely, that of explicating truth's nature, of, indeed, thinking that truth is a relation holding between the thinkable (the propositional) and the unthinkable (non-propositional reality). The Identity theorist cannot take this last step, for it is obvious to her that "reality," whatever that is to mean, must be itself thinkable. For how else could one ever expect to explain the normative draw that truth exerts upon us? What interest could we really have in establishing by enquiry whether our thought stands in a privileged relation-one among countless unprivileged others, for on the correspondence conception, there is surely some fact to which the proposition that $2+2=3$ corresponds in some way ${ }^{15}$ - to a reality which lies beyond that with which we can engage in thought? Without the central idea that it is reality itself which serves as the contents of our thoughts when those contents are true, we cannot see our way through to the goal of that weaker notion. It is undeniable that there is an understanding of reality and thought's engagement with it implicit in the identity conception of truth, but I shall maintain that it too is one which does not stray far from common sense and, indeed, underwrites what it is in truth that is intellectually irresistible. This understanding is picked up in Section 5; first, a word on deflationism. ${ }^{16}$

\footnotetext{
14 That his 1904 intrinsicist view of truth, while standing against idealism, failed to provide such an explanation, Russell found troubling: "It may be said - and this is, I believe, the correct view - that there is no problem at all in truth and falsehood; that some propositions are true and some false, just as some roses are red and some white [...] But this theory seems to leave our preference for truth a mere unaccountable prejudice, and in no way to answer to the feeling of truth and falsehood" (Russell, 1904, p. 523).

15 As though the name "Sam" could be the name of Sam simply because it stood in some relation to him.

16 This discussion of Wright's approach is indebted to conversations with Rose Ryan Flinn.
} 
Both the rendering of Frege's argument and the discussion of Wright above made much of the normative nature of truth and its attendant connection with enquiry. The identity theorist, then, must hold that truth, while unanalysable, is nonetheless a substantial property. And in holding that it is a substantial property predicable of thinkables, the identity theorist makes explicit her opposition to the deflationary conception. For she sees no need to regard truth as a merely logical property, the nature of which is wholly exhausted by the Equivalence Schema. ${ }^{17}$ Horwich $(1998$, p. 5) writes on the contrary that

The entire conceptual and theoretical role of truth may be explained on [the basis of the instances of the Equivalence Schema]. This confirms our suspicion that the traditional attempt to discern the essence of truth - to analyse that special quality which all truths supposedly have in common - is just a pseudo-problem based on syntactic overgeneralisation. Unlike most other properties, being true is unsusceptible to conceptual or scientific analysis. No wonder that its 'underlying nature' has so stubbornly resisted philosophical elaboration: for there is simply no such thing.

On what basis, however, is the inference from truth's unsusceptibility to analysis to its having no underlying nature warranted ${ }^{18}$ To be clear, the identity theorist has no quarrel with the attendant claim that the role of a truth predicate is to serve the logical purpose of enabling generalisation over thinkables. But its being able to do so is secured by the fact that the predicate marks out what is thought by the speaker to be common to the thinkables generalised. We can make no sense of a speaker's desire to generalise in this way until and unless we have attributed to her the capacity to recognise a distinction between truth and falsehood, which is necessarily prior to her need to use a truth predicate to generalise in the way that that expression permits. For what logical need for such a predicate would there be in the absence of the capacity to recognise the distinction it marks? Having seen how, via Frege's argument, the temptation that lies behind correspondence theories of truth, alongside all other putative reductive analyses of truth, may be resisted, the identity theorist sees no need to deflate truth's nature to the vanishing point.

Horwich (1998, pp. 9-10) characterises this kind of view as holding

that truth is an indefinable, inexplicable quality that some propositions simply have and others simply lack - a fundamental property of which no account can be provided. This gives the sense of impenetrable mysteriousness to the notion of truth and can be the resort only of those who feel that the decent alternatives have been exhausted.

The identity theorist agrees that the property of truth is indefinable-she well knows the lesson of Frege's argument. But that does not entail that it is inexplicable, and she has to hand an elucidation: A thinkable is true if and only if it is a fact. One might be here tempted to ask for an explanation of some thinkable's being a fact: "Why is it a fact

17 Even less so would she see any need to regard truth as characterised by the sum of instances of the Tschema for a language, since true sentences are not facts.

18 Indeed, this is a point on which the identity theorist and Wright are in agreement and which forms the basis of their resistance to deflationism. 
that snow is white?". But unless one has a prior commitment to the form that such an answer must take-a prior commitment to an account of facts-an answer need be no different from that given to someone who asks of some non-vacuously true instance of the Equivalence Schema for an explanation of why the right-hand side holds; that is, no different from the answer given to the question: "Why is snow white?"

\section{TWO REALMS}

I left Section 2 by putting forward a conception of facts to which many are likely to object: Facts are true thinkables. But are not facts worldly items, the constituents of which are objects and properties? In that case, if a fact is a true thinkable, then must not objects and properties be the constituents of thinkables?

Construing the identity theorist's claim in this way, that is, by insisting that facts involve worldly constituents, would be to present one version of what Dodd (2000, p. 112) has called a robust identity theory:

A robust identity theorist [...] takes facts to be states of affairs: things with objects and properties as constituents. Such an identity theory is appropriately labelled 'robust' because it preserves the idea, present in correspondence theories, that true propositions - in addition to their parts - have worldly relata. A robust identity theorist agrees with the correspondence theorist that each true proposition stands in a relation to a state of affairs; she departs from correspondence theorists by taking the relation in question to be that of identity. If the robust identity theorist is correct, a true proposition is a chunk of reality.

Such a line of thought is likely to put one in mind of Russell who, at one time, conceived of judgement as a multiple relation holding between a thinker and the objects, including $n$-ary relations, which, for him, constituted the thinkable that the thinker judged.

That Russell's view is not, in this form, an identity conception of truth is evident when one sees that it entails a correspondence conception of truth, for that in virtue of which some thinkable is true is the existence of a complex object-what he sometimes calls a fact-which has the constituents of the thinkable as its constituents too. The judgement that Etna is a mountain is true because there exists a complex object involving Etna and mountainhood, perhaps as its constituents; the judgement that Etna is a tractor is false because no corresponding complex object exists. ${ }^{19}$ One might retreat to a version of an earlier view of Russell's and hold that a judgement is true just in case a propositional unity, having worldly objects as its constituents, which is the content of a judgement, both exists and in some or other sense obtains. ${ }^{20} \mathrm{~A}$ judgement is false when the

19 As Candlish (1999b) notes (p. 209, n.18), versions of this view are present in Russell's writings from 1906 to 1918, but there is a particularly clear statement in "On the nature of truth and falsehood": "If A loves B, there is such a complex object as 'A's love for B' and vice versa; thus, the existence of this complex object gives the condition for the truth of the judgement 'A loves B'. And the same holds in all other cases" (Russell, 1910, p. 123).

${ }^{20}$ While Russell is clear about the nature of propositions ("But a proposition, unless it happens to be linguistic, does not itself contain words: It contains the entities indicated by words" [Russell, 1937, §51]), he 
propositional unity, having worldly objects as its constituents, exists but does not obtain. This would be a robust view in Dodd's sense. But even if one could make sense of how this conception of facts might illuminate a notion of truth, such a view is disruptive of the opacity of belief. Facts, conceived of in this way, are individuated extensionally, their identities governed by sameness of constituent, so that the judgements that Hesperus is Phosphorus and that Hesperus is Hesperus involve the same fact, namely, that containing Venus. If the true thinkables which are the contents of those judgements are facts, then what we would on independent grounds hold to be two distinct judgements appear to be just one.

Against a robust identity theory of truth, Dodd (2000, pp. 111-2) introduces, and supports, a modest conception according to which

... propositions are construed as [Fregean] thoughts, and facts are identified as thoughts that are true. The resulting identity theory is best described as 'modest' because, in its denial that facts are 'full-blooded denizens of the real world' (Dummett, 1973, p. 153), it repudiates the idea that true propositions as a whole, in addition to their sub-propositional constituents, have worldly relata. For the modest identity theorist, language/world relations are entirely sub-sentential.

The modesty of a modest identity theory of truth is characterised by its therapeutic aims: The "modest identity theory's role is purely critical," and it "would not so much as exist were it not for the correspondence theory" (Dodd, 2000, p. 125). In giving us reason to suppose that a fact may be nothing other than a true thought, reason to believe that we need not conceive of facts (or any other entity other than ordinary objects of reference and properties) as playing a role in truth-making, the modest identity theorist seeks to provide a corrective to correspondence conceptions of truth.

One could be forgiven for thinking that this is simply a terminological move, the repurposing of the word "fact" so as to mean "true thought," for the view seems to leave the entire apparatus of the correspondence conception intact. Fregean Thoughts have components - their "sub-propositional constituents"-standing in relations to the objects and properties of reference. ${ }^{21}$ But once we have this picture in mind-a picture according to which there is a gap between the components of Thought and worldly objects-we may find ourselves tempted to ask under what worldly conditions the Thought expressed by the sentence "Snow is white" is true and will not be satisfied by an answer-When it is a fact! - which avails itself of entities situated within the realm of sense. For an identity theory to achieve its therapeutic ends, it must, it seems, dissolve the possibility of asking such questions.

Unsurprisingly therefore, Dodd endorses minimalism about truth: The expression "is true" has as its point only the servicing of certain logical needs. This is not something with which I would wish to disagree. Having, however, allowed himself to speak of objects of reference and properties and having made the metaphysical claim that these

does not put the truth claim quite as I have: "True and false propositions alike are in some sense entities, and are in some sense capable of being logical subjects; but when a proposition happens to be true, it has a further quality, over and above that which it shares with false propositions" (Russell, 1937, §52).

${ }^{21}$ I shall, from here, reserve the capitalised "Thoughts" for Fregean Thoughts, which have as their components "sub-propositional components." 
are distinct from the components of Thoughts, he leaves something to be said about what must be the case with them when a Thought involving them is a fact. It is that space which correspondence theorists wish to fill with their talk of "facts," "states of affairs," and so forth. Banishing the vocabulary does nothing to disguise the void. To use some words of Hornsby's (1997, p. 21) to different effect, "a philosopher who thought to ask 'What is truth?' may not be satisfied by being told what sort of device the truth predicate is: she wants to know what sort of distinction it records." Having invited us to consider a world of objects and properties as related to, and yet separate from, the constituents of true Thoughts, this dissatisfaction seems doubly the case when the modest identity theorist makes a retreat to a minimalist treatment of truth. ${ }^{22}$

These considerations press, I take it, a dilemma in respect of the status of the relationship between facts and objects as conceived of by an identity theorist. On the one hand, we have it that objects are constituents of facts, and are therefore, if the identity conception of truth is correct, also the constituents of true thinkables. We saw that such a view must deal with the respect in which, on independent grounds, judgements are individuated more finely than facts. On the other hand, we have it that true thinkables, and so facts, are Fregean Thoughts having as their components "sub-propositional constituents" standing in relations to worldly objects. We saw that such a view, merely by rescuing the term "fact" and embracing a minimalist theory of truth, fails to relieve the impetus of a correspondence conception of truth.

As it happens, I do not think that this dilemma is a real one but rather emerges from the false dichotomy implicit in Dodd's distinction between robust and modest identity theories of truth which arises from what is common to his account of each. Robust and modest theories differ insofar as, in the former case, thinkables as a whole have worldly relata, while in the latter case, they do not. What they have in common is that each kind of theory takes thinkables to have "sub-propositional components," which have worldly relata.

Now, the word "worldly" is one that may conjure up any number of ideas, but I think that what Dodd intends may be brought out by his mention of a realm of reference, to be contrasted with a realm of sense, which is supposed to "capture an important and intuitive distinction: that between reality and our thought about it" and which is "understood to contain the things we think about minus thoughts and their constituents." The world, according to Dodd (2000, p. 181), is just this realm of reference:

[I]t can only be misleading to say that the true thought that the book is red is in the world, but that the book itself is not. I think most people would agree that a rough approximation of what is meant by "the world" has it that the world is made up of things our thoughts are about.

\footnotetext{
${ }^{22}$ Indeed, the version of a correspondence theory of truth that Field (1986) discusses is one that turns not upon a correspondence between propositions and their truthmakers but between the constituents of propositions and their worldly correlates. This is what Sher (2013) has called a non-traditional correspondence theory of truth. Such a view yields, for Field, "correspondence truth conditions," and a sentence's (or proposition's) having such correspondence truth conditions was sufficient, for him, to set it against deflationary conceptions of truth.
} 
This last quote contains an objection against Hornsby's view, which Dodd finds "incoherent." In her 1999 response to Dodd (1999) and Candlish (1999a), Hornsby describes herself, against Dodd's claim that her view is robust, as "more or less happy" with his attribution to her of the thesis that thinkables are in the realm of sense (p. 242). Dodd takes this qualified acceptance as an admission that her view is, after all, modest (though Hornsby nowhere describes her view using this word).

This, combined with Hornsby's rejection of the assumption that facts have, in Dodd's words, "objects and properties as constituents" while still holding that the world is a world of facts, leads Dodd to conclude that Hornsby is committed to an incoherence: Objects are not in the world, while true thinkables-facts-are. ${ }^{23}$

While I cannot speak for Hornsby, I do not imagine that she takes herself to be involved in any such incoherence. What is being rejected, I should think, is the idea that objects and properties, conceived of as denizens of a realm of reference distinct from those of the realm of sense, are involved in facts. Dodd's insistence on there being some metaphysical distinction to be drawn between two such realms is what, as we saw, rendered his conception of a modest identity theory of truth such as to provoke correspondence intuitions. Rejecting that distinction may make it seem as though what we are rejecting is a realm of sense in favour of retaining a realm of reference so that whatever the details of our identity theory, it must be robust, in which case our earlier dilemma resurfaces. Or it may make it seem that what we are rejecting is a realm of reference in favour of a realm of sense, in which case thought floats free of reality. No wonder the picture that I am presenting flickers before the eyes. But I say that we should reject the distinction, and when I say that, I do not mean that we should reject one part of it: I say that we should reject it.

Talk of two realms may lead one to the view that the constituents of thinkables and the constituents of reality stand apart. This may then lead one to think that there is a way of talking about the constituents of reality-a way of talking about a realm of reference - which, as it were, answers directly to those constituents. That is what talk of "objects and properties" amounts to when it is not talk of particular (ordinary) objects and particular (ordinary) properties, or understood as a mere shorthand for talking generally of particular (ordinary) objects and particular (ordinary) properties. And when we do speak of particular (ordinary) objects and properties, anyone who sees any value in the notion of sense will not be tempted to suppose that our so speaking involves a way

\footnotetext{
23 Johnston (2013, pp. 394-5). makes a related objection: "For my judgement to be a judgement that Jack loves Jill, [Hornsby] holds, is for it have as its object the proposition-entity that Jack loves Jill - and it remains obscure, a point in need of substantial account, how the truth of that entity and so the truth of the judgement will depend on things being a certain way with Jack and Jill. [...] In having thinkables as things, Hornsby places them alongside, and so at a distance from, other, more normal things such as Jack and Jill. In so having thinkables, this is to say, there arises a question of how matters being as they are with the thinkable-things - in particular their being true and their entailing each other - relates to matters being as they are with the non-thinkable things - their being red, loving each other etc." What Johnston's objection, like Dodd's, turns upon is an assumption according to which talk of "more normal things" (like talk of "the world") can be given an articulation according to which those things are apprehensible in thought or talk independently of their (internal) relation to what is thinkable.
} 
of talking that answers directly to anything other than the (ordinary) objects and properties of which we are speaking. ${ }^{24}$

This point can be brought out by clarifying that of which a notion of sense is supposed to remind us: that there is no talking of an object which is not one way, among others, of talking about it, no thinking of an object which is not one way, among others, of thinking about it. And this in turn is to acknowledge the multi-faceted nature of external things and the fact that multi-facetedness is reflected in thought's engagement with the world. When Frege (1960) says that no explanation of the cognitive differences of the terms that renders the sentence "the morning star is the evening star" substantive should rob the discovery that underwrites its truth of its status as astronomical, what he means to fend off is the idea that all that we have discovered is that we had, all along, two different ways of thinking about Venus. To be sure, when we discover that Hesperus and Phosphorus are both Venus, we discover that we had previously two ways of thinking of Venus, but that follows from facts we have discovered about astronomy. But if one thinks of a realm of sense standing wholly apart from a realm of reference, it is very hard to see how that discovery could be anything other than a discovery about the occupants of the realm of sense, none of which are astronomical bodies. In order to secure what Frege rightly demands, we must see that ways of thinking of things are internally connected to those things and so reject the two realms view and see that the ways in which an object can be thought about-the senses which constitute thinkables-stand at no distance from the object itself. ${ }^{25}$

\section{JOHNSON'S REBUKE}

Sullivan (2005) has criticised Hornsby's view for failing to reconcile two apparently opposed, but equally meritorious, conceptions of the world: in the one corner, we have the Tractarian world, which is a totality of Facts and which is wholly thinkable, and in the other, the Johnsonian world, which is a world of kickable things (I use the capitalised "Facts" to indicate the notion employed in the Tractatus). Like Dodd, Sullivan sees Hornsby as having won the first at the cost of the second. The Tractatus, we are told, effects a reconciliation of these strands by having Tractarian objectsobjects which cannot be grasped in significantly different ways-be the constituents of thinkables, while complex objects-those ordinary objects displaying the "cussedness," the "multi-facetedness and contingency" of external things (p. 59)—constitute the external world. The reconciliation is achieved when we see both that Facts are arrangements of Tractarian objects so that it is right to say that a true thinkable is a Fact, and that Facts constitute complex objects (this is why, for Wittgenstein, the world's being a world of Facts and not of [Tractarian] things is compatible with its being a world of complex objects). The complexity of complex objects is thus manifested by their characteristic susceptibility to being grasped in significantly different ways, that

${ }^{24}$ Indeed, when Frege tries to specify some of the constituents of the realm of reference in just this way, he finds himself in, if not paradox, aporia. See Frege (1951).

${ }^{25}$ Further problems may yet unfurl themselves from talk of realms: There is the question, the focus of Russell's (1905) Gray's Elegy argument, as to the nature of the relation that holds between a sense and its referent, as well as the considerations that inspired Davidson's (1968) paratactic account of propositional attitude reports. 
is, by their amenability to throw up different Facts depending on the angle of conceptual approach. Complex objects-ordinary objects-thus conceived are "not left over as something outside the (F)acts," for proper analysis of expressions involving reference to such complex objects will terminate in truth functions of elementary propositions, which, if true, are just what is the case, that is, are Facts. And so a charge of transcendental idealism to the effect that there is a disconnect between what is thinkable-Facts-and what unthinkably constitutes external reality is defused: nothing - no thing - is left outside of the Facts, and so nothing — no thing - is left outside of the thinkable.

Now, on this view, determining whether complex objects-ordinary objects-can satisfy the Johnsonian requirement is a delicate matter. For in aiming his foot at the stone, Johnson was not pointing out that it had one side among many. He was pointing out its reality, its primacy, and its permanence: in short, its intractability to reconstruction from anything internal to the mind. That the Tractarian view cannot answer the charge of idealism signalled by the kick can be seen if we think through what kind of answer that view must give to an appeal for an explanation of the primacy of ordinary objects in our thought about the world.

Take, as an example, a proper name like "Hesperus." That name, on Tractarian analysis, is to resolve itself into a descriptive expression, perhaps inordinately truthfunctionally complex and having as its arguments elementary propositions, which are themselves arrangements of names standing for simple objects (e.g., 3.24). This expression expresses that Tractarian objects are arranged in some or other way; an expression which has as its content, in other words, Facts. A similar procedure will yield, for the expression "Phosphorus," a partially different expression which may have as its content some of the same Facts as are expressed in the first expression, but certainly some Facts which are not (for otherwise there would be no difference to the senses of the sentences in which "Hesperus" and "Phosphorus" are interchanged). Analysis will likewise show that Venus is a complex containing both Hesperus and Phosphorus, in the sense that the Facts invoked in the analysis of "Venus" will be at least all of the Facts invoked in the analysis of "Hesperus" and "Phosphorus."26

But when should this procedure end? When, that is, can we be said to have exhausted the complex object which is the referent of each of "Hesperus," "Phosphorus," "Venus," and so forth? It seems that any such constraint, far from being furnished by the world, must be internal to thought. The world, according to the Tractatus, consists of all the Facts: all of the arrangements of simple objects that obtain. Some combinations of those Facts are the complex objects that are the focus of our thought about the world. But there are combinations of Facts which, while no less real than the complex objects to which we attend, are of no interest to us. There is thus nothing that privileges which of those combinations should be the complex objects which feature in our thought about the world. What we pick out as things-that planet, Venus, for instance-is a feature of - is internal to-our thought and without external constraint. That Venus enjoys a status in our conception of the world that the complex consisting of Venus and Mars does not is a feature of our psychology and our natural languages. Perhaps this is as Wittgenstein intended it-why some of the vast range of available complexes stand in

\footnotetext{
${ }^{26}$ This reconstruction turns on a realist view of the objects of the Tractatus and is thus not compatible with the kind of exegesis presented by Ishiguro and others: see Ishiguro, 1969. I take it, however, that the realist construal is implicit in Sullivan's (2005, p. 58) take on the Tractatus, for how else could "objects figure in their own right in propositions"?
} 
the light for us, while others linger ever in the dark is an empirical question, the answer to which will refer to commonalities among human thinkers in respect of biology, perceptions of salience, interests, activities, and so forth. Even the world itself, conceived of as the total of Tractarian Facts, and thus a complex object in its own right, stands as a candidate for the only object of our interest. ${ }^{27}$

A proliferation of complex objects characterised in this way, however, may seem to fail to capture what was intended to be captured by an informative identity statement. At a time at which it was not believed that Hesperus is identical to Phosphorus, the analysis of each of those names would yield sentences expressing truth functions of partly different elementary propositions. The referents of those expressions would thus reveal themselves to be two quite distinct complex objects. We must then see future assent to the claim "Hesperus $=$ Phosphorus" not as indicating a new piece of knowledge about some common object but as expressing a conceptual shift such that the union of those complex objects is to be identified as the object relevant to our enquiries. ${ }^{28}$

Put another way, the Tractatus thus fails to respect the constraint that the astronomical discovery that Hesperus is Phosphorous should be just that, an astronomical discovery; rather, it is best characterised, as a discovery about us. It fails to do so because, in an attempt to reconcile the two conceptions-a world of Facts and a world of kickable things-it treats the complexity and multi-faceted nature of complex objects as consisting in those objects' being constituted by facets, which are themselves complex objects. In so doing, the Tractatus cannot satisfy the Johnsonian rebuke: When Johnson swung his foot at the stone, it was not the world as a whole at which he was taking aim.

Sullivan takes Hornsby (and McDowell) to identify true thinkables, and therefore facts, with Fregean Thoughts. But so doing may import into Hornsby's view items to which she is not committed. For him, Thoughts' constituents are "cognitive relata that completely determine a mind's cognitive relation to them" (Sullivan, 2005, p. 59). Their completely determining their relation to the mind in this way is what ensures that they meet the requirement of explaining the opacity of belief, for they meet the standard "same item-same grasp; different grasp-different item." Such items can have no complexity of the kind exhibited by ordinary objects. And so the objection goes, if the world is a world of facts, and facts are true Thoughts, then we can find no place for ordinary, multifaceted objects within it.

Sullivan confesses that this is "an extraordinary charge to bring against a leading advocate of object-dependent senses," namely, McDowell, and it will be clear that my earlier animadversions against the two-realm view are heavily indebted to Evans. ${ }^{29} \mathrm{It}$ will not, however, be good enough, according to Sullivan, to reply to this objection by

27 This conclusion is not related to the slingshot argument: that argument turns on the possibility of treating facts as the referents of expressions, which the theory of the Tractatus rules out.

${ }^{28}$ Wittgenstein $(1922,5.53-5.534)$ rejected the idea that identity is a real relation holding between objects but instead interpreted "=" as expressing a rule for substitution of terms. My reconstruction of the Tractarian view of complexes provides a supplementary form of explanation for why he should have treated identity in this fashion, that is, as expressing a rule about the expressions in our language rather than as featuring in genuine claims concerning the referents of those expressions.

${ }^{29}$ Evans, 1982, though it is, in fact, McDowell (1977) who is clearest that a notion of sense need not carry any ontological baggage beyond a commitment to expressions and their referents. 
pressing the object-dependent view of sense on which an alignment of mind with senses is an alignment with references, since this is to misconstrue the focus of the objection. Sullivan does not take his point to depend on the "not universally wrong" descriptive view of sense but rather sees it as a blow against McDowell's characterisation of reality.

How, then, should an identity theorist characterise reality, and the ordinary objects that we find therein? Anyone impressed with my aims in these preceding passages must disagree with Sullivan's (2005, n.6) contention that "the descriptive conception of sense is, after all, not universally wrong." For such a conception insists that we may, if we reflect carefully enough upon the meanings of our words, say what the sense of some expression is and in so doing will find ourselves irretrievably bound up in a conception of sense according to which such items may feature as objects of singular reference in locutions such as

\section{A. The sense of "Afla" $=\ldots$.}

There can nonetheless be a point in the deployment of descriptive expressions as a part of the business of getting a speaker to see the way in which an object is to be thought of if they are to grasp the meaning of a candidate expression. That business may be a messy one, involving additionally some or all of the apparatus (ostension, correction, repetition, and so forth) involved in the induction of a novice into the use of an expression for a community of speakers. And there can be a point in seeing a competent speaker's utterance of, or assent to, sentences involving descriptive content as expressing beliefs about an object, which are revealing of the way in which they think about it. The point of each is that they serve the twin purposes of imparting to or eliciting from a speaker knowledge of the sense of the expression in question, knowledge which is shown, and not stated, by a speaker's implicit understanding that

B. "Afla" refers to Afla.

An elaboration on the idea of the sense of an expression as a way of thinking about an object, always one way among others, inseparable from the object itself, may draw us towards themes elsewhere explored by McDowell in connection with perception. He seeks to show that it is an unquestioned assumption of a gap between mind and world that presents the philosopher with a false choice between coherentism and the Myth of the Given in explicating the role of perceptual experience in rational discourse (1994). Similarly, that false choice asserts itself in respect of the contents of thought when we delude ourselves that only a correspondence conception of truth may protect against the idealist threat implicit in coherentism. To say that the content of what one thinks can be the case - can be a fact-is to reject a false distinction (and not simply one part of it) between the kinds of things that can be present in thought and the kinds of things that are present in the world (where the world is just all that is the case). Rather, that is a conception of reality, which starts from what is truly thought and takes its stock of things from there; whether the content of my thought is true involves us in a different question, one that, given there can be no general standard, is not the philosopher's question to answer.

McDowell (1994, p. 107) writes that "if we want to identify the conceptual realm with the realm of thought, the right gloss on 'conceptual' is not 'predicative' but 'belonging to the realm of Fregean sense" That is, the correct characterisation of "conceptual" will involve an account of ways of thinking of objects which do not collapse into descriptive specification. But nor can it involve either an account which sets the idea of a 
thinkable's truth adrift from its anchor in a world whose nature is (largely) independent of thinkers, as does coherentism, nor an account of truth which fails to explain the value of a thinkable's truth, as does the conception of truth as a relation between the thinkable (the propositional) and the unthinkable (non-propositional reality), which invite correspondence intuitions. To involve the latter would be to leave the normative features of truth entirely inexplicable, and I have here been arguing against that direction of travel. It might be thought that to reject the relational conception is to dislocate thought from truth's objectivity. Hornsby (1997, pp. 14-15) provides a clear inductive argument, exploiting the modality inherent in the notion of a thinkable, which shows that the identity theorist has all the resources to allow of unthought thinkables, some of which are facts, and thus to preserve common-sense realism about facts' independence from thinkers.

Such a defence is, however, only one half of a defence against idealism, for it leaves the Johnsonian anxiety unquelled. The Tractarian solution remained open to the accusation that our thought of external things is a "frictionless spinning in the void," because it locates the constraint on what we take to be such objects in empirical facts about us. A catalogue of what is in the heavens and on the earth is then mind conditioned; a catalogue of the occupants of external reality that included Hesperus and Phosphorus without including Venus need not be seen as evidence of error on the author's part so much as other-mindedness. But realism of the Johnsonian kind demands foreclosure on such possibilities.

The identity theorist promotes a conception of objects according to which the ways in which they can be thought about-can occur in thinkables-are features of those very objects - that is, that there is an internal relation between objects and the ways in which they can be thought about, and thus between objects and the thinkables in which they may occur. This is, in a very important sense, a conception according to which what is real and what may feature in a thinkable coincide; the full characterisation of that conception awaits, admittedly, development. But the modality implicit in a way of thinking of an object may be brought to bear in favour of Johnsonian realism, the view that the natures of multi-faceted and contingent objects of ordinary reference are independent from thinkers.

There is an unseen side of the moon. That should not lead one to think that in seeing the moon, one sees anything less than the moon, except in the most trivial sense. The unseen side of the moon is, nonetheless, seeable, just not by us as we are currently oriented in physical space in respect of it (this, of course, does not prevent us from amassing a great deal of knowledge about it). Likewise, there are ways of thinking of the moon-and nothing less than the moon-which feature in thinkables, some true, which are not yet, and may never be, thought by anyone, just as there are ways of thinking of the moon which feature in thinkables, some of which are true, which we do think but which our ancient forebears were not able to think. Whether the thinkables in which such ways of thinking about the moon occur become available to us will be a matter of our future orientation towards it in conceptual space. ${ }^{30}$

${ }^{30}$ My thanks are owed to the participants at a conference on Identity Theories of Truth held at Trinity College, Cambridge, and also to those at the Trinity College, Dublin, Philosophy Colloquium, both in 2016. Cheryl Misak, Rose Ryan Flinn, Robert Trueman, Peter Sullivan, and Dan Waxman provided, at various points, very useful comments or encouragement, for which I am most grateful. I especially thank Stephen Williams, Sabina Lovibond, Michail Peramatzis, Andrea Christofidou, Kate Tunstall, and Martin Pickup, all members of Worcester College's Philosophical Work in Progress Group, who commented on an early draft 


\section{REFERENCES}

Ambrose, A. (1935a). Finitism in mathematics (I). Mind, 44(174), 186-203.

Ambrose, A. (1935b). Finitism in mathematics (II). Mind, 44(175), 317-340.

Austin, J. L. (1979). Unfair to facts. In Urmson, J. O. and Warnock, J. G., editors, Philosophical Papers, 3rd edition, 154-177. Oxford: Oxford University Press.

Baldwin, T. (1991). The identity theory of truth. Mind, New Series, 100(1), 35-52.

Beall, J. C. (2000). On the identity theory of truth. Philosophy, 75(291), 127- 130.

Candlish, S. (1989). The truth about F. H. Bradley. Mind, New Series, 98(391), 331-348.

Candlish, S. (1999a). Identifying the identity theory of truth. Proceedings of the

Aristotelian Soceity, New Series, vol. 99, 233-240.

Candlish, S. (1999b). A prolegomenon to an identity theory of truth. Philosophy, 74(288), 199-220.

Cartwright, R. (1987). A neglected theory of truth. In Philosophical Essays, Cambridge, MA: MIT Press.

Davidson, D. (1968). On saying that. Synthese, 19(1-2), 130-146.

Dodd, J. (2000). An Identity Theory of Truth. Basingstoke: Macmillan Press.

Dummett, M. (1973) Frege: Philosophy of Language. 1st edition. London: Gerald Duckworth \& Co.

Dummett, M. (1981). Frege: Philosophy of Language. 2nd edition. London: Duckworth.

Evans, G. (1982). The Varieties of Reference. McDowell, J., editor. Oxford: Oxford University Press.

fact, n., int., and adv. (June 2017). OED Online. www.oed.com/view/ Entry/67478. [Accessed 10 January 2018].

fault, v. (June 2017). OED Online. www.oed.com/view/Entry/68602. [Accessed 10 January 2018].

Field, H. (1986). The deflationary conception of truth. In MacDonald, G. and Wright, C., editors, Fact, Science and Morality. Oxford: Basil Blackwell Ltd.

Frege, G. (1951). On concept and object. Mind, 60(238), 168-80. Trans. P.T. Geach and M. Black.

Frege, G. (1956). The Thought: A logical inquiry. Mind, 65(259), 289-311. Trans. A. M. Quinton and M. Quinton.

Frege, G. (1960). On Sense and Reference. Trans. Black, M., in Black, M., and Geach, P.T., editors, Translations from the Philosophical Writings of Gottlob Frege, $2^{\text {nd }}$ edition. Oxford: Basil Blackwell.

Hornsby, J. (1997). Truth: The identity theory. Proceedings of the Aristotelian Society, New Series, 97, 1-24.

of this paper and who provided an, as always, exquisite environment in which to present work in its most cautious and embryonic form. 
Hornsby, J. (1999). The facts in question: A response to Dodd and Candlish. Proceedings of the Aristotelian Society, New Series, 99, 241-5.

Horwich, P. (1998). Truth. $2^{\text {nd }}$ edition. Oxford: Oxford University Press.

Ishiguro, H. (1969). Use and reference of names. In Winch, P., editor, Studies in the Philosophy of Wittgenstein, London. Routledge and Kegan Paul.

Johnston, C. (2013). Judgement and the identity theory of truth. Philosophical Studies: An International Journal for Philosophy in the Analytic Tradition, 166(2), 381-97.

Künne, W. (2003). Conceptions of Truth. Oxford: Clarendon Press.

McDowell, J. (1977). On the sense and reference of a proper name. Mind, New Series 86(342), 159-85.

McDowell, J. (1994). Mind and World. Cambridge MA: Harvard University Press.

Russell, B. (1904). Meinong's theory of complexes and assumptions (iii). Mind, New Series, 13(52), 509-24.

Russell, B. (1905). On Denoting. Mind, New Series, 14(56), 479-493.

Russell, B. (1910). On the nature of truth and falsehood. In Slater, J.G., editor, assisted by Frohmann, B., (1992), Logical and Philosophical Papers 1909-13 (The Collected Papers of Bertrand Russell, vol. 6), London and New York: Routledge.

Russell, B. (1936). The limits of empiricism. Proceedings of the Aristotelian Society, New Series, Vol. 36, 131-150.

Russell, B. (1937). The Principles of Mathematics, $2^{\text {nd }}$ edition. London: George Allen \& Unwin.

Sher, G. (2013). Introduction to, and commentary on, Jennifer Hornsby's “Truth: The Identity Theory". In Longworth, G., editor, Truth: Proceedings of the Aristotelian Society, volume The Virtual Issue No. 1, 205-213.

Strawson, P. F. (1950). Truth. Proceedings of the Aristotelian Society, Supplementary Volumes, 24, Physical Research, Ethics and Logic, 129-156.

Sullivan, P. M. (2005). Identity theories of truth and the Tractatus. Philosophical Investigations, 28(1), 43-62.

Wittgenstein, L. (1922). Tractatus Logico-Philosophicus. London: Kegan Paul, Trench and Trübner.

Wright, C. (1998). Truth: A traditional debate reviewed. Canadian Journal of Philosophy, 28(Sup1), 31-74. 